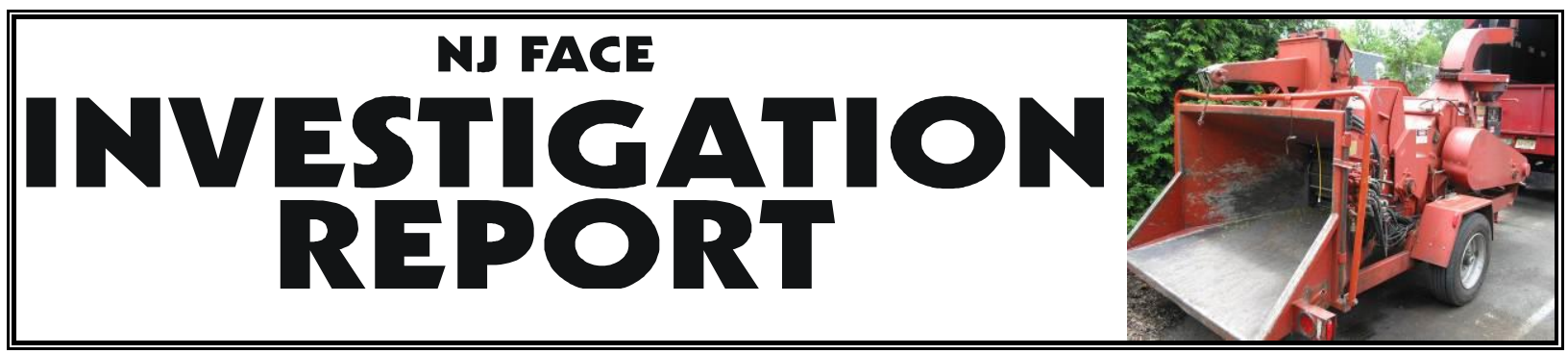

Fatality Assessment \& Control Evaluation Project

FACE 12-NJ-024

August 27, 2013

\title{
Mechanic Crushed Underneath Four-ton Wood Chipping Machine
}

A 54-year-old male mechanic at a tree trimming and removal company died after being crushed underneath an 8,000-pound wood chipping machine at a maintenance yard. On the day of the incident, the decedent and another worker were attempting to change the brakes on the wood chipper. They were using a telescopic hydraulic jack to lift the chipper in order to remove the wheels. After one side of the wood chipper was lifted, a single jack stand (rated for three-tons, used in a pair) was placed under that side. The decedent went underneath the machine attempting to properly position the hydraulic jack on the axle to lift the other side. The jack slipped, the jack stand broke, and the wood chipper fell on top of the decedent, killing him.

Contributing Factors

- Working under a load/ overhead hazard

- Proper load considerations

- Work practices

NJ FACE investigators recommend that these safety guidelines be followed to prevent similar incidents:

- The machine should be lifted one side at a time, and then cribbed and blocked to prevent movement.

- Jack stands should be selected according to the appropriate loading capacity, and are used and rated in pairs.

- An expander should be used on the floor jack saddle to avoid having the worker going underneath the machine.

- A safety and health plan based on a job hazard analysis should be developed by the employer and followed where workers are assigned tasks. 


\section{INTRODUCTION}

In spring of 2012, NJ FACE staff was notified of the death of a 54-year-old male mechanic who was crushed underneath a three-ton wood chipping machine at the maintenance yard of a tree service company in northern NJ. The victim had worked for the tree company for approximately eight years and was very experienced with many of the pieces of equipment. Employee health and safety training, as well as job training, was conducted on site by the employer.

The OSHA Area office contacted NJ FACE and a concurrent investigation was conducted. Additional information was obtained from the medical examiner's report, death certificate, and police report.

\section{INVESTIGATION}

The incident occurred on a clear, mild spring day (mean daily temperature was $62^{\circ} \mathrm{F}$ ). There was no significant precipitation recorded. The incident took place on flat concrete outside the maintenance garage of a large tree care company in northern NJ (Figure 1). On the day of the incident, two workers were assigned to change the brakes on the wheels of an 8,000 pound wood chipper (Figure 2). To lift the machine, the workers used a 22/35 ton, two-stage air-operated, telescopic hydraulic floor jack (Figure 3). An air/hydraulic jack is a hydraulic jack that is actuated by compressed air, eliminating the need for the user to actuate the hydraulic mechanism. ${ }^{1}$ The compressed air actuation of the hydraulic jack is accomplished by depressing the valve lever. The jack operated in two stages to allow a greater lifting height. In the first stage, the first ram piston had a lift range of $15 \% \frac{3}{8}$ " (with a maximum load of 35 tons), and the second stage had a lift range up to 19 1/2" (with a maximum load of 22 tons). The hydraulic jack had an extension screw (which could extend $3 \frac{1}{8} \%$, and the extension was included in the maximum lift range value).

After one side of the wood chipper was lifted with the hydraulic jack and the wheel removed, a single three-ton jack stand was placed underneath the vehicle (Figure 4). The deceased then removed the jack and walked around the machine to lift the other side. While on the opposite side of the machine, the deceased went underneath the machine to align the saddle of the jack to the center of the axle. While still underneath the machine, using the air valve lever, he activated the jack. As the jack ram ascended, the saddle kicked out and the jack stand snapped in half at the column (Figure 4). The wood chipper then dropped down, crushing the victim underneath. 
FIGURE 1. Maintenance garage and wood chipper similar to the one involved in the incident.
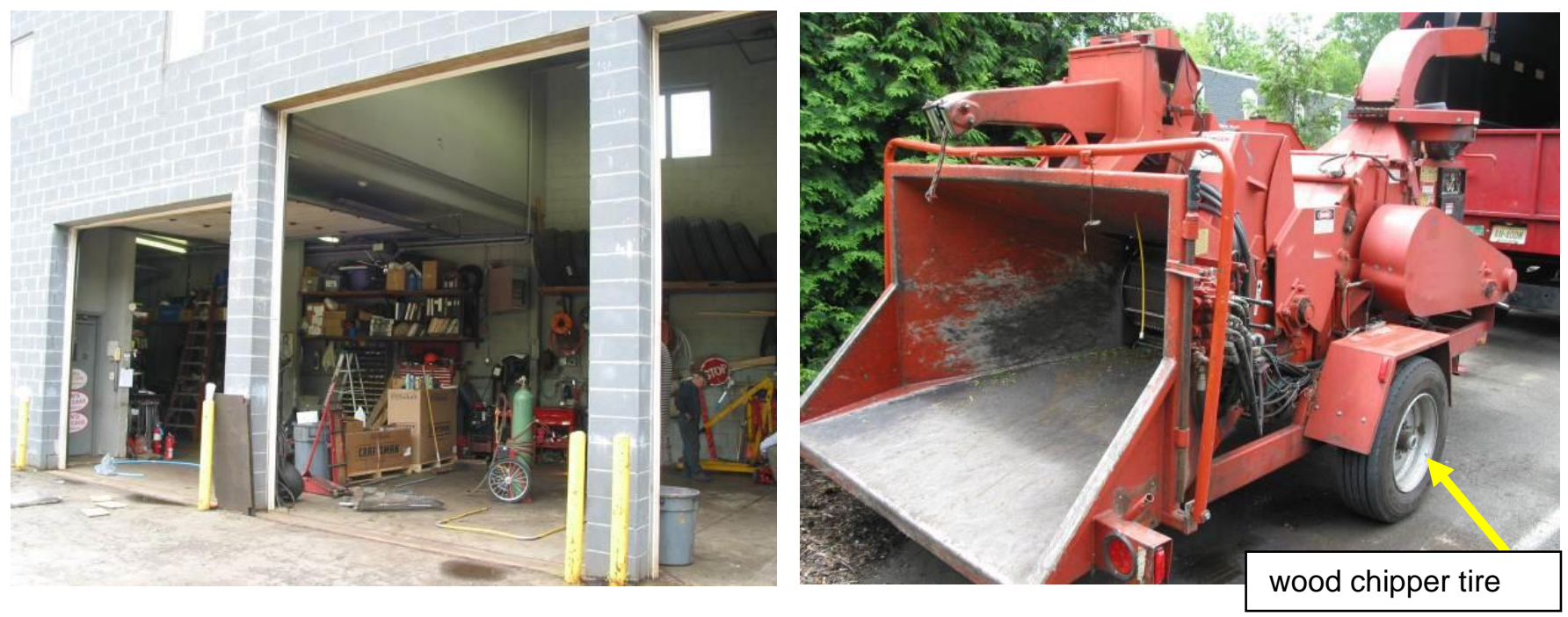

FIGURE 2: Wood chipper, views from the side and from underneath.
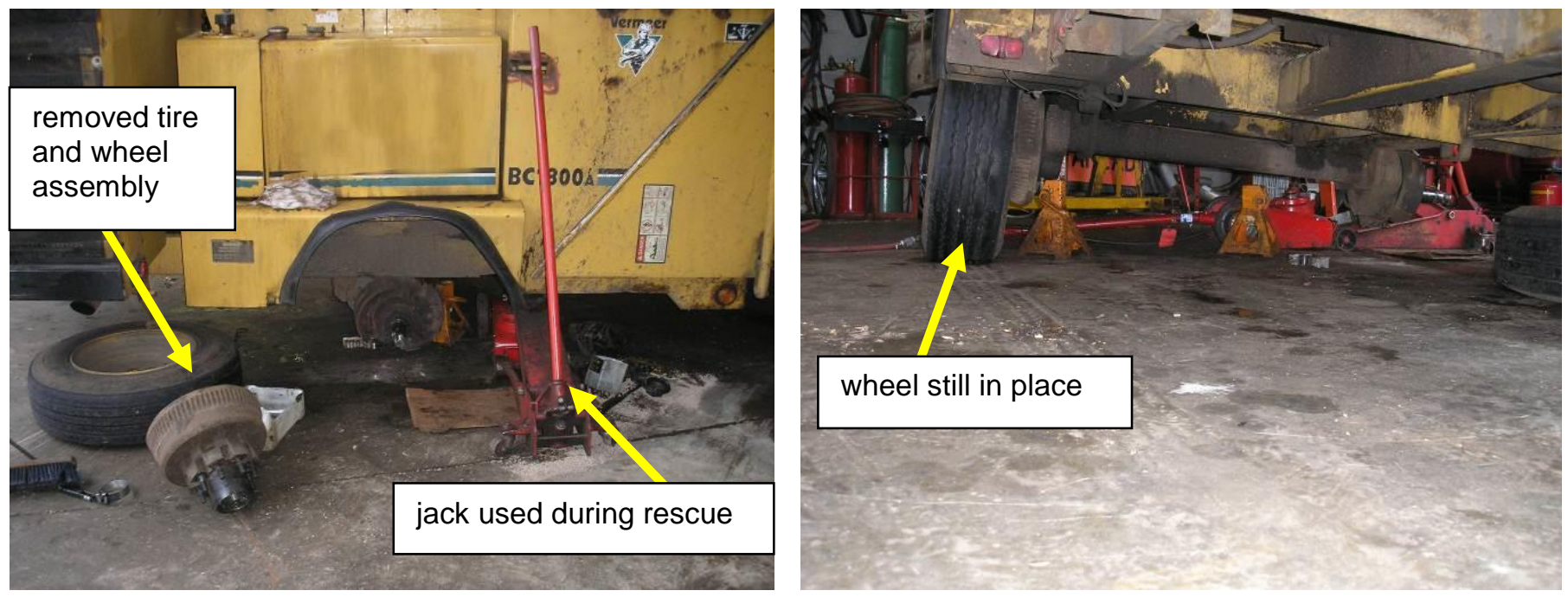
FIGURE 3. Air/hydraulic jack used to lift wood chipper.

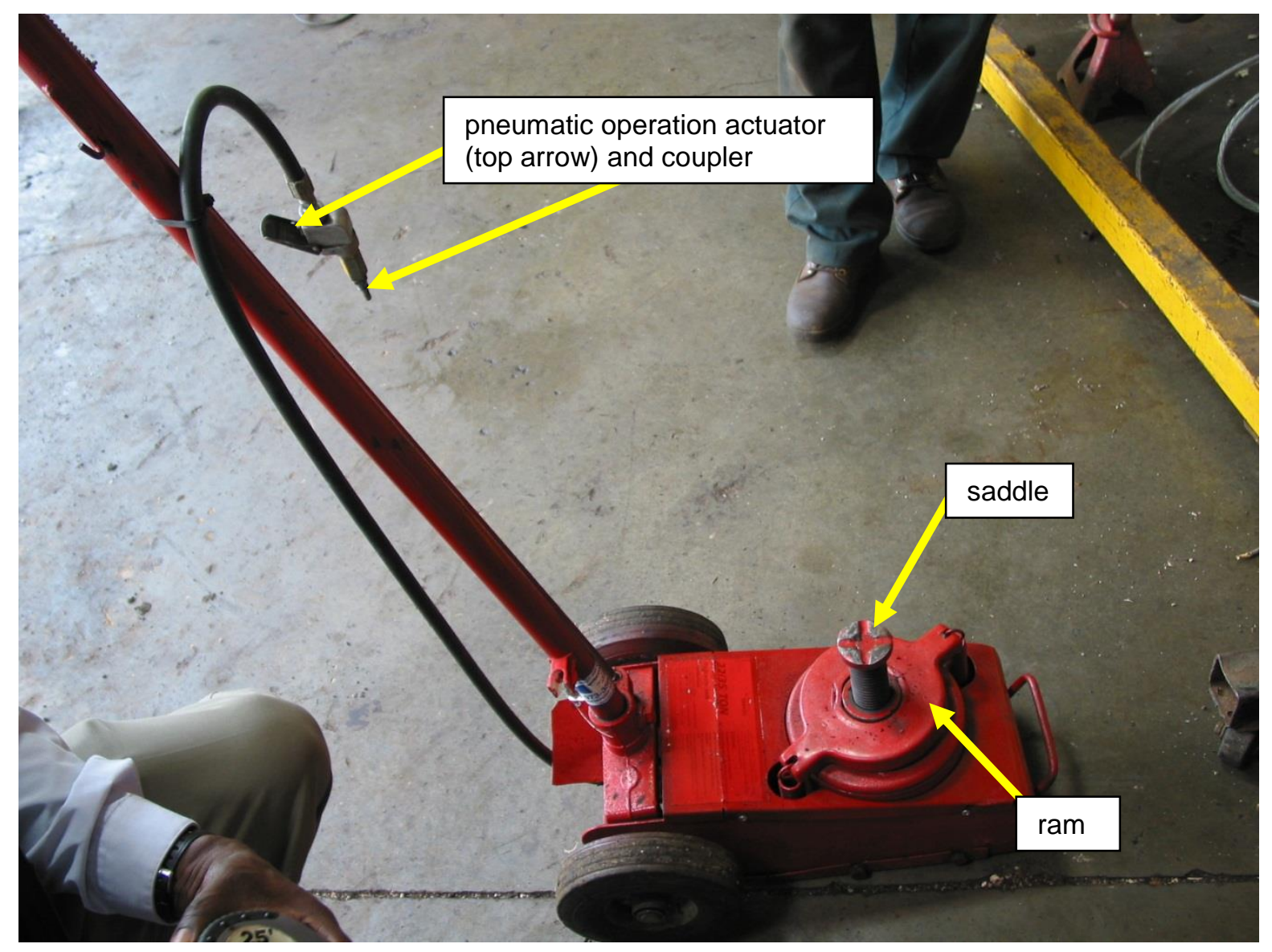


FIGURE 4. Column of three ton jack stand that snapped in half, and close-up

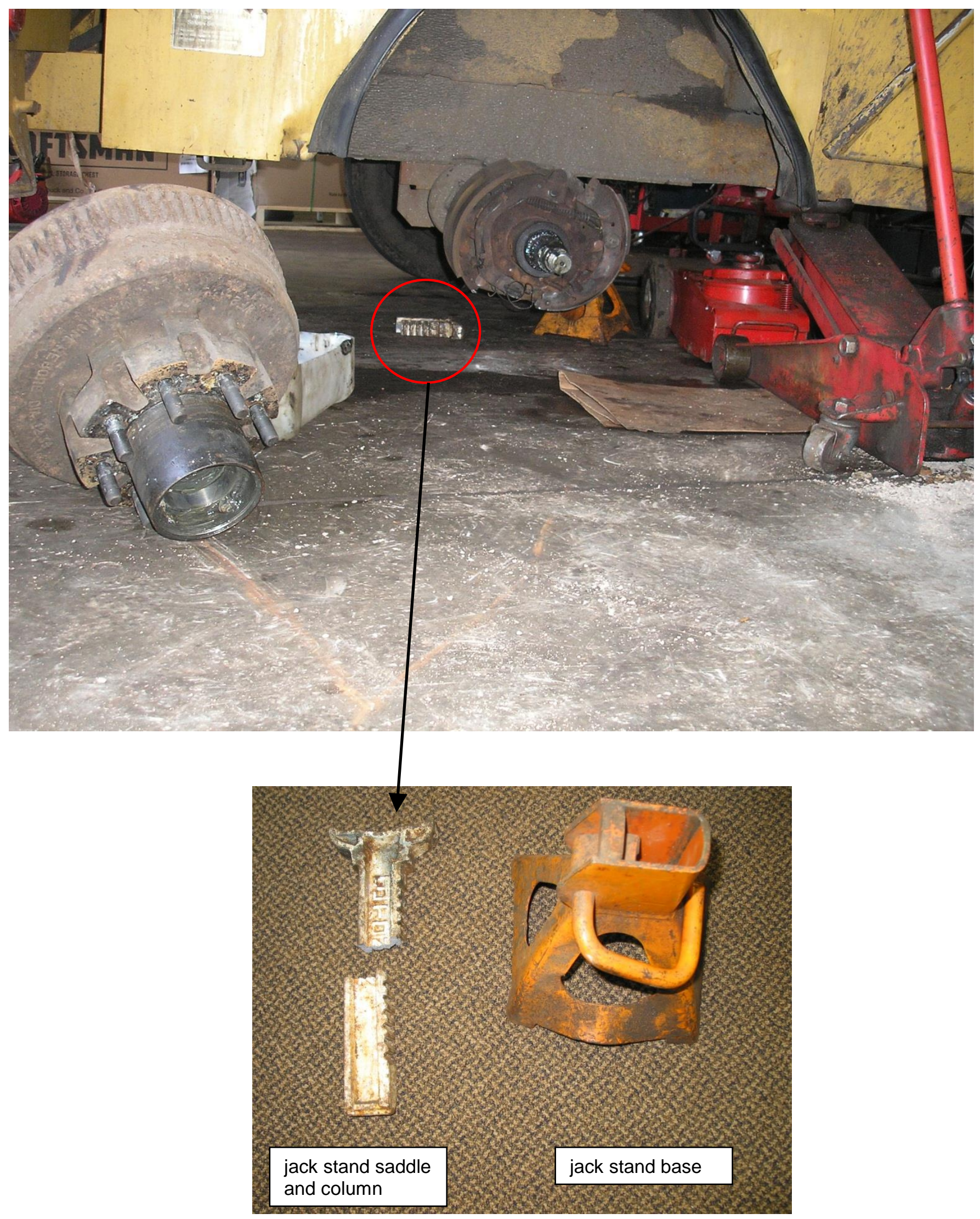


Recommendation \#1: The machine should be lifted one side at a time, cribbed and blocked to prevent movement, and the appropriate pair of jack stands used.

\section{Discussion:}

In order to safely change the wheel brakes on the wood chipping machine, the recommended procedure from the manufacturer is as follows: 1) using a jack with the proper loading capacity, lift one side of the machine; 2) block/crib the machine to prevent movement; 3) use a pair of properly rated jack stands (reach under, do not go under to place jack stands); 4) after completing work, remove jack stands (slightly lift machine first), lower machine; 5) repeat procedure for other wheel.

In this incident, the deceased attempted to lift both wheels while working on the brakes. In addition, only one jack stand was used per side. Jack stands must be used in pairs on a single side. ${ }^{2}$ Cribbing or blocking the machine is also very important and could have been done if one side was lifted at a time.

\section{Recommendation \#2: Jack stands should be selected according to the appropriate loading capacity, and are used and rated in pairs.}

\section{Discussion:}

As mentioned above, and as can be found in ANSI/ASME PALD-2009, jack stands should be used in pairs and are rated as such. In other words, the rating that is posted on an individual jack stand does not refer to that particular stand, but rather to a pair of the same (Figure 5 ). ${ }^{2}$

Figure 5. Rating capacity of a jack stand is established for a pair.

\section{3-ton 3-ton}

Recommendation \#3: An expander should be used on the floor jack saddle to avoid having the worker going underneath the machine.

\section{Discussion:}

As seen in Figure 3, the floor jack had a narrow saddle. NJ FACE recommends that this be widened either via purchase of an extender, or through manufacturer's design/production. The width of the lifting point (crossbeam) the victim was using was similar to that of the saddle, making it necessary for him to go underneath the machine to adjust the alignment. Examples of recommended expanded saddles can be 
seen in Figure 6. With a wider saddle, the need for adjustment could have been avoided.

Figure 6. Examples of expanded saddle.
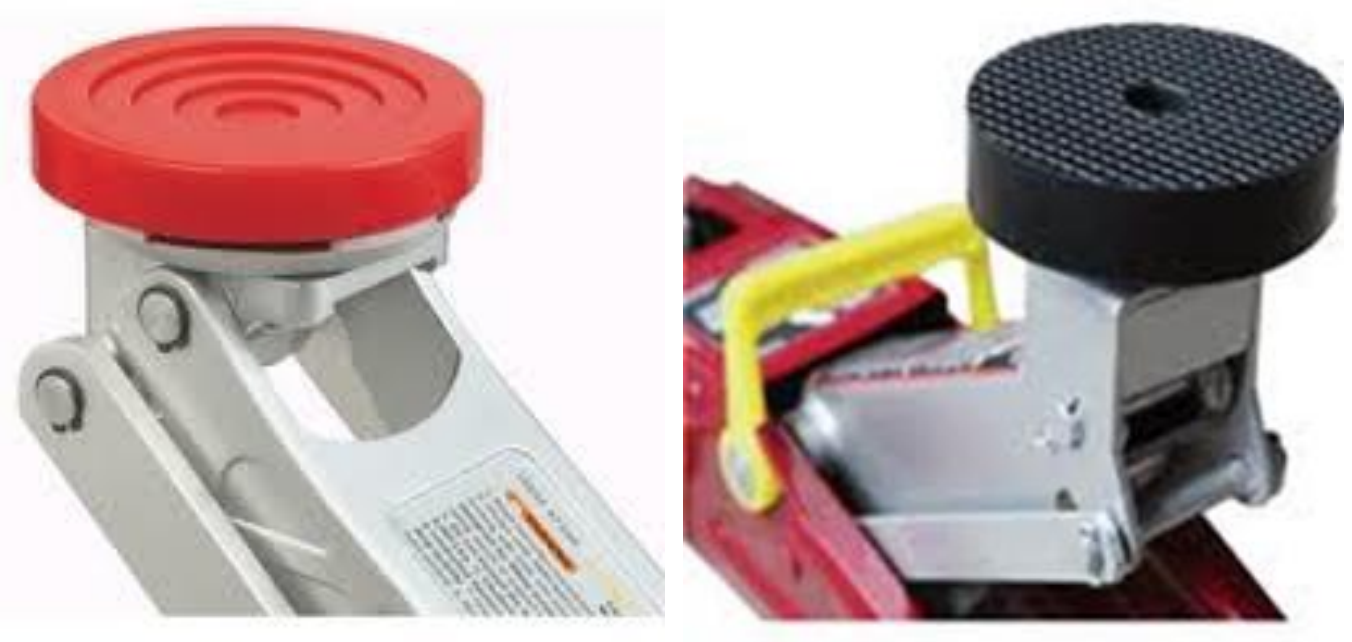

Recommendation \#4: A safety and health plan based on a job hazard analysis should be developed by the employer and followed where workers are assigned tasks.

Discussion: Employers should conduct a job hazard analysis, with the participation of employees, of all work areas and job tasks. ${ }^{3}$ A job hazard analysis should begin by reviewing the work activities for which the employee is responsible and the equipment that is required. Each task is further examined for mechanical, electrical, chemical, or any other hazard that the worker may encounter. 


\section{APPENDIX}

\section{RECOMMENDED RESOURCES}

It is essential that employers obtain accurate information on health, safety, and applicable OSHA standards. NJ FACE recommends the following sources of information which can help both employers and employees:

\section{U.S. Department of Labor, Occupational Safety \& Health Administration (OSHA)}

Federal OSHA can provide information on safety and health standards on request. OSHA has several offices in New Jersey that cover the following counties:

第 Hunterdon, Middlesex, Somerset, Union, and Warren counties...................732-750-3270

Essex, Hudson, Morris, and Sussex counties............................................973-263-1003

Bergen and Passaic counties..................................................................201-288-1700

留 Atlantic, Burlington, Cape May, Camden, Cumberland, Gloucester,

Mercer, Monmouth, Ocean, and Salem counties. $856-757-5181$

Web site: www.osha.gov

\section{New Jersey Public Employees Occupational Safety and Health (PEOSH) Program}

The PEOSH Act covers all NJ state, county, and municipal employees. Two state departments administer the Act; the NJ Department of Labor and Workforce Development (NJDLWD), which investigates safety hazards, and the NJ Department of Health (NJDOH) which investigates health hazards. PEOSH has information that may also benefit private employers.

NJDLWD, Office of Public Employees Safety

羿Telephone: 609-633-3896

Web site: www.nj.gov/labor/lsse/lspeosh.html

$\underline{\text { NJDOH, Public Employees Occupational Safety \& Health Program }}$

粱Telephone: 609-984-1863

Web site: www.nj.gov/health/peosh

On-site Consultation for Public Employers

留Telephone: 609-984-1863 (health) or 609-633-2587 (safety)

Web site: www.state.nj.us/health/eoh/peoshweb/peoshcon.htm 
New Jersey Department of Labor and Workforce Development, Occupational Safety and Health On-Site Consultation Program

This program provides free advice to private businesses on improving safety and health in the workplace and complying with OSHA standards.

留Telephone: 609-984-0785

Web site: www.nj.gov/labor/lsse/lsonsite.html

\section{New Jersey State Safety Council}

The New Jersey State Safety Council provides a variety of courses on work-related safety. There is a charge for the seminars.

幦Telephone: 908-272-7712.

Web site: www.njsafety.org

\section{Internet Resources}

Other useful Internet sites for occupational safety and health information:

- $\mathrm{CDC} / \mathrm{NIOSH}-w w w . c d c . g o v / n i o s h$

- USDOL Employment Laws Assistance for Workers and Small Businesses - www.dol.gov/elaws

- National Safety Council - www.nsc.org

- NJDOH FACE reports - www.nj.gov/health/surv/face/index.shtml

- CDC/NIOSH FACE - www.cdc.gov/niosh/face/faceweb.html

- OSHA - www.osha.gov

- ANSI - www.ansi.org

\section{REFERENCES}

1. Elliott, B. Compressed Air Operations Manual, $1^{\text {st }}$ Ed. McGraw Hill-Professional. Pgs 1-407

2. ASME/ANSI PALD-2009. Safety Standard for Portable Automotive Lifting Devices; 2009, pp $1-64$.

3. Job Hazard Analysis. US Department of Labor Publication \# OSHA-3071, 1998 (revised). USDOL, OSHA Publications, PO Box 37535, Washington DC 20013-7535 


\section{Fatality Assessment and Control Evaluation (FACE) Project Investigation \# 12-NJ-24}

This report was prepared by staff members of the New Jersey Department of Health's Occupational Health Surveillance Unit. The goal of FACE is to prevent fatal work-related injuries by studying the work environment, the worker, the task, the tools the worker was using, the energy exchange resulting in the fatal injury, and the role of management in controlling how these factors interact. FACE gathers information from multiple sources that may include interviews of employers, workers, and other investigators; examination of the fatality site and related equipment; and reviewing OSHA, police, and medical examiner reports, employer safety procedures, and training plans. The FACE program does not determine fault or place blame on employers or individual workers. Findings are summarized in narrative investigation reports that include recommendations for preventing similar events. All names and other identifiers are removed from FACE reports and other data to protect the confidentiality of those who participate in the program.

NIOSH-funded state-based FACE Programs include: California, Iowa, Kentucky, Massachusetts, Michigan, New Jersey, New York, Oregon, and Washington. Please visit the NJ FACE Web site at www.nj.gov/health/surv/face/index.shtml or the CDC/NIOSH FACE Web site at www.cdc.gov/niosh/face/faceweb.html for more information.

The NJ FACE Project is supported by the Centers for Disease Control and Prevention (CDC). The contents of this report are solely the responsibility of the authors and do not necessarily represent the official views of the CDC.

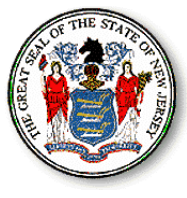

Public Health Services Branch Division of Epidemiology, Environmental and Occupational Health Occupational Health Surveillance Unit (609) 826-4984 nj.gov/health/surv/face/index.shtml 